\title{
The Role and Therapeutic Potential of NF-kappa-B Pathway in Severe COVID-19 Patients
}

\author{
Apurva Hariharan $^{2} \cdot$ Abdul Rahman Hakeem $^{1}$ (C) Subathra Radhakrishnan ${ }^{3} \cdot$ Mettu Srinivas Reddy $^{1} \cdot$ \\ Mohamed Rela ${ }^{1}$
}

Received: 20 August 2020 / Accepted: 25 October 2020 / Published online: 7 November 2020

(c) Springer Nature Switzerland AG 2020

\begin{abstract}
Coronavirus disease 2019 (COVID-19) pandemic has affected health care systems worldwide. Severe presentations of COVID-19 such as severe pneumonia and acute respiratory distress syndrome (ARDS) have been associated with the postviral activation and release of cytokine/chemokines which leads to a "cytokine storm" causing inflammatory response and destruction, mainly affecting the lungs. COVID-19 activation of transcription factor, NF-kappa B (NF- $\mathrm{kB}$ ) in various cells such as macrophages of lung, liver, kidney, central nervous system, gastrointestinal system and cardiovascular system leads to production of IL-1, IL-2, IL-6, IL-12, TNF- $\alpha$, LT- $\alpha$, LT- $\beta$, GM-CSF, and various chemokines. The sensitised NF- $\mathrm{BB}$ in elderly and in patients with metabolic syndrome makes this set of population susceptible to COVID-19 and their worse complications, including higher mortality. Immunomodulation at the level of NF- $\kappa B$ activation and inhibitors of NF- $\kappa B$ (IкB) degradation along with TNF- $\alpha$ inhibition will potentially result in a reduction in the cytokine storm and alleviate the severity of COVID-19. Inhibition of NF-кB pathway has a potential therapeutic role in alleviating the severe form of COVID-19.
\end{abstract}

Keywords COVID-19 $\cdot \mathrm{NF}-\mathrm{kb} \cdot$ Cytokine storm $\cdot$ Therapeutic role $\cdot$ Immunomodulation $\cdot$ SARS $\cdot$ MERS

\section{Introduction}

On 31 December 2019, Wuhan Municipal Health Commission, China, reported a cluster of cases of pneumonia in Wuhan, Hubei Province. A novel coronavirus was identified from these patients, and subsequently on 12 January 2020, the genetic information of the novel coronavirus $(\mathrm{nCoV})$ was published (Wu et al. 2020a). After full-genomic sequencing and phylogenetic analysis, it was obvious that the coronavirus that causes COVID-19 is a beta-coronavirus in the same subgenus as the severe acute respiratory syndrome (SARS) virus which caused the SARS-CoV epidemic in 2003. The structure of the receptor-binding gene region is very similar

Mohamed Rela

mohamedrela@gmail.com

1 The Institute of Liver Disease and Transplantation, Dr. Rela Institute and Medical Centre, Bharath Institute of Higher Education and Research, Chennai, Tamilnadu, India

2 SRM Medical College Hospital and Research Centre, Chennai, Tamilnadu, India

3 National Foundation for Liver Research, Chennai, Tamilnadu, India to that of the SARS coronavirus; and the virus uses the same receptor, the angiotensin-1-converting enzyme 2 (ACE2), for cell entry (Zhou et al. 2020).

There has been a steady surge in the number of COVID19 cases worldwide which has crossed 40 million, with more than 1,131,000 deaths and is still on the rise (COVID19 Coronavirus Pandemic Update Worldometer Info 2020). In about $14 \%$ of patients, the virus causes severe disease, including pneumonia and acute respiratory distress syndrome (ARDS). About $5 \%$ of patients suffer critical disease, including respiratory failure, septic shock, multi-organ failure and death (Williamson et al. 2020).These critically ill patients appear to have significantly higher levels of proinflammatory mediators and cytokines, suggestive of a "cytokine storm syndrome" (Gao et al. 2019).

Hyper-activation of the nuclear factor kappa-light-chainenhancer of activated B cells (NF- $\kappa \mathrm{B})$ pathway has been implicated in the pathogenesis of the severe/critical COVID19 phenotype (Hirano and Murakami 2020). During previous coronavirus outbreaks, such as SARS-CoV and the Middle East Respiratory syndrome coronavirus (MERS$\mathrm{CoV}$ ), it was reported that viral proteins such as nsp1, nsp3a, nsp7a, spike, and nucleocapsid protein all caused excessive 
NF- $\kappa \mathrm{B}$ activation, possibly contributing to severe disease and high case-fatality rate (DeDiego et al. 2014; Oeckinghaus and Ghosh 2009; Liao et al. 2005). Herein, we review current literature on the effect of SARS-nCoV-2 infection on $\mathrm{NF}-\kappa \mathrm{B}$ activation and discuss the potential therapeutic role of inhibitors of this pathway in the treatment of COVID-19.

\section{NF-KB and the inflammatory response}

$\mathrm{NF}-\kappa \mathrm{B}$ is a complex system of proteins present inactive in the cytoplasm along with inhibitory proteins that are known as inhibitors of NF- $\mathrm{KB}$ (IкBs). Upon stimuli (induc-

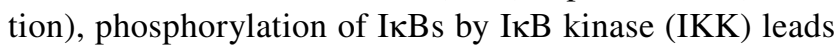
to nuclear translocation of NF- $\mathrm{KB}$, binding to their cognate DNA and activates transcription of a wide variety of genes involved in host immunity, inflammation, cell proliferation and apoptosis (Oeckinghaus and Ghosh 2009). The $\mathrm{NF}-\kappa \mathrm{B}$ inducers are highly variable and include bacterial lipopolysaccharides, ionizing radiation, reactive oxygen species (ROS), cytokines such as tumour necrosis factor alpha (TNF- $\alpha$ ) and interleukin 1-beta (IL-1 $\beta$ ) and viral DNA and RNA (Zhang et al. 2017). The activated NF-кB transcription factors promotes the gene expression of wide variety of cytokines (e.g., IL-1, IL-2, IL-6, IL-12, TNF- $\alpha$, $L T$ - $\alpha, L T-\beta$, and GM-CSF), chemokines (e.g., IL-8, MIP-1, MCP1, RANTES, and eotaxin), adhesion molecules (e.g., ICAM, VCAM, and E-selectin), acute phase proteins (e.g., Serum Amyloid A; SAA), and inducible effector enzymes (e.g., inducible nitric oxide synthase; iNOS and cyclooxygenase-2; COX-2). Thus NF- $\mathrm{kB}$ serves as a 'rapid acting' primary transcription factor which can regulate various cellular responses such as host's early innate immune response to infection, and also associated with chronic inflammatory states, viral infections, septic shock syndrome and multiorgan failure (Zhang et al. 2017; Li and Verma 2002). In addition, the constitutive activation of NF- $\mathrm{KB}$ pathways has been reported in inflammatory diseases such as multiple sclerosis and rheumatoid arthritis (Liu et al. 2017).

\section{NF-kB, cytokine storm and coronavirus associated infections}

Since the emergence of COVID 19, in most severe cases an elevated level of proinflammatory factors such as, IL-2, IL-1, IL-6, IFN- $\gamma$, MIP1 $\alpha$, MCP1 and TNF- $\alpha$ have been reported (Tang et al. 2020; Costela-Ruiz et al. 2020). The infiltrating phagocytic cells such as monocytes and macrophages are responsible for the "cytokine storm" seen in some COVID-19 patients. Similarly, the inflammatory cells infiltration and diffuse pulmonary alveolar injury has been reported for patients with SARS-CoV and MERS-CoV (Soy et al. 2020).
NF- $\mathrm{KB}$ signal transduction pathway is considered as a prototypical proinflammatory pathway (Lawrence 2009). A study on SARS-CoV which was responsible for the worldwide outbreak of SARS in 2003 showed that the SARS-CoV nucleocapsid protein (N protein) activates NF- $\mathrm{KB}$ in Vero E6 cells in a dose dependent manner (Liao et al. 2005). In parallel, SARS-CoV lacking the Envelope (E) gene (SARSCoV- $\Delta$ E) showed reduced expression of proinflammatory cytokines, diminished neutrophil infiltration, reduced lung pathology which resulted in increased BALB (albino, immunodeficient and inbred strain) mice survival (DeDiego et al. 2014; Day et al. 2009). DeDiego et al. (2014) in an elegant study proved that inhibitors of NF- $\mathrm{KB}$ pathway increased the survival rate in both in vitro and in vivo (in mice) studies with reduced lung pathology. In vitro studies in the previous SARS epidemic have shown that the spike (S) protein induces a strong cytokine response in infected mononuclear cells through the NF- $\kappa \mathrm{B}$ pathway. This cytokine response was initiated through Toll-like receptor (TLR) activation through a protein kinase $\mathrm{C}$ dependent pathway of NF- $\mathrm{kB}$ and could be inhibited by NF- $\mathrm{kB}$ blockade (Dosch et al. 2009). Thus focussing on understanding how NF- $\mathrm{KB}$ signalling regulates the inflammatory responses will aid in developing strategies to mitigate the "cytokine storm" and reduce the pathology of severe COVID-19. In addition, identifying potential therapeutic targets associated with the NF- $\mathrm{KB}$ pathway will help us to manage the more severe spectrum and mortality associated with the pandemic.

\section{Multi-channel activation of NF-KB in coronavirus associated infections}

SARS-nCoV-2 is a novel virus in the Coronaviridae family that has single stranded positive RNA genomes. During the replication of positive stranded RNA virus, production of a negative-stranded copy of the genome is a crucial step. The negative strand is used as a template for genome replication by the viral RNA-dependent RNA polymerase (Knoops et al. 2008). In the course of SARS-nCOV-2, multiplication within the host cell results in production and accumulation of dsRNA (called transcriptive intermediate) in the cellular cytoplasm. The interferon-induced dsRNA-dependent protein kinase (PKR) is a threonine kinase which arrests translation within host cells in response to viral infection, an innate immune mechanism against viral replication (Garcia et al. 2009; Meusel et al. 2002). In addition, upon binding to dsRNA, the PKR (gets activated as a kinase enzyme), which also activates the inhibitor of IкB kinase (IKK),

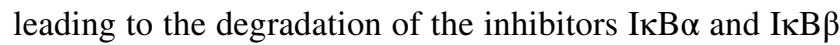
and the concomitant release of NF- $\kappa B$ (Williams 1999; D'Acquisto et al. 2002). NF- $\mathrm{kB}$ transcription factors translocate into the nucleus where they bind to specific elements called $\kappa \mathrm{B}$-sites and initiate transcription and production of 
'proinflammatory mediators' (D'Acquisto et al. 2002). This activation of NF- $\kappa B$ is called the "canonical pathway" as $\mathrm{NF}-\kappa \mathrm{B}$ essential modulator (NEMO), a regulatory subunit of the IKK complex is involved (Fig. 1). Along with the direct activation of NF- $\kappa B$ pathway, the PKR also mediates TNF- $\alpha$ (15), which activates NF- $\kappa B$ pathway via "noncanonical pathway". NF- $\mathrm{kB}$ signalling also happens because of the stimulation of a subset of the tumour necrosis factor superfamily receptors (TNFRs) through B-cell activating factor receptor (BAFF), Lymphotoxin $\beta$ or CD40. This is non-canonical pathway (without NEMO) although slow, is more long lasting in terms of proinflammatory mediator production, when compared to the canonical activation (Fig. 1) (Dorrington and Fraser 2019).

One of the other major pathways through which beta coronavirus causes hyperactivation of NF- $\kappa \mathrm{B}$ is via the myeloid differentiation primary response 88 (MyD88) pathway through pattern-recognition receptors (PPRs) (Fig. 1) (D'Acquisto et al. 2002; Birra et al. 2020). This leads to induction of a variety of cytokines including IL- 6 , TNF- $\alpha$ and chemokines (Hirano and Murakami 2020). This was shown as a major factor in the higher case-fatality rates associated with SARS and MERS, when compared to COVID19 (Wit et al. 2016). The increase in angiotensin II (AngII) caused by reduced level of angiotensin converting enzyme II (ACE2) membrane protein which is endocytosed along with $\mathrm{n}$-CoV has been implicated in the progression of lung injury and propagation of severe inflammation due to dysregulation of renin-angiotensin pathway (RAS) (Ingraham et al. 2020). AngII acts as a proinflammatory cytokine via angiotensin1-receptor (AT1R), the latter also activates NF-kB, disintegrin and metalloprotease 17 (ADAM17) (Devaux et al. 2020). These three lead to production of epidermal growth factor receptor (EGFR) ligands and TNF- $\alpha$, which lead to a vicious cycle of further activation of NF- $\mathrm{KB}$ and propagation of "cytokine storm" (Fig. 1) (Gao et al. 2019; Hirano and Murakami 2020).

The Janus Kinase (JAK) and signal transduction and activator of transcription factor 3 (STAT3) pathway is required for full activation of the NF- $\mathrm{KB}$ pathway and its main stimulator is IL-6. The IL-6 when binds to its receptor activates JAK-STAT pathway allows phosphorylated STAT3 to

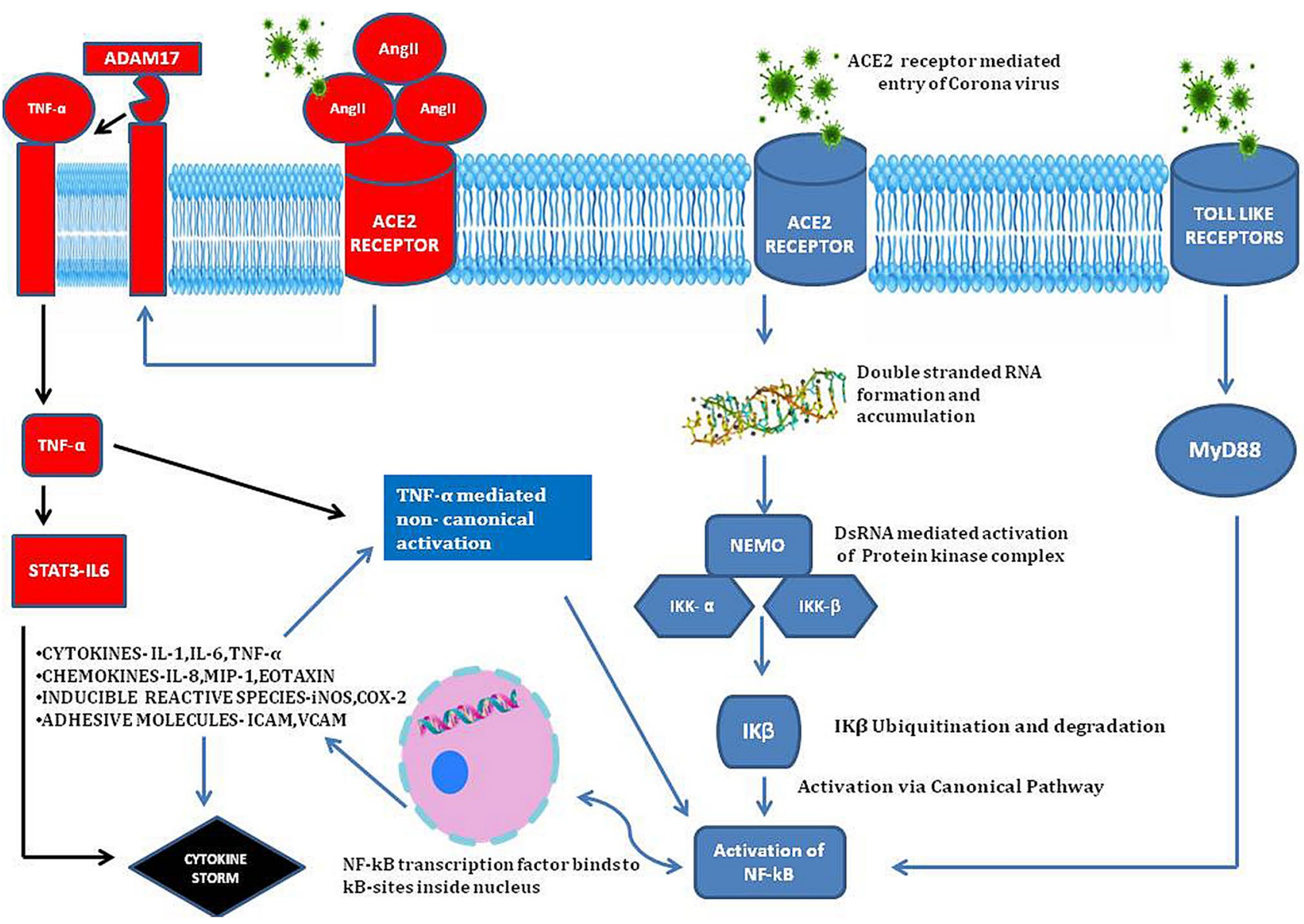

Fig. 1 Schematic diagram explaining the mechanism of action of NF- $\mathrm{KB}$ in COVID-19 via various pathways leading to "cytokine storm syndrome" 
translocate into the nucleus which promotes IFN- $\gamma$ reduction and induce cytokine release syndrome. In vascular tissues, the activated NF- $\kappa$ B produces IL-6. Thus in COVID-19, both NF- $\mathrm{BB}$ and JAK-STAT pathway can be constitutively activated, which in turn can hyperactivate the IL-6 amplifier response (IL-6 Amp), which can lead to a cascade of hyper-activation of NF- $\mathrm{BB}$ by STAT3, leading to multiinflammatory responses (Hirano and Murakami 2020; Battagello DS, 2020; Brasier 2010). IL-6 is also considered as an important marker of cellular senescence, with rates increasing with age, all of which explains the higher mortality in elderly age group. The MAPKs are serine-threonine protein kinases involved in the modulation of cellular responses during stress and pathophysiological states. Coronaviruses have been shown to involve all the three MAPKs (the Jun aminoterminal kinases (JNK), P38 and extracellular signal-regulated kinases (ERK1/2)) pathways for viral pathogenesis. P38 mitogen-activated protein kinases (MAPKs) mediated cross-talk activation of NF- $\kappa$ B was reported by Saccani et al. (2002). Elevated levels of Ang II mediates its adverse reactions via P38 MAPK pathway activation (Park et al. 2007). P38 MAPK pathway regulates the translation of cytokines TNF- $\alpha$ and IL- $1 \beta$ which can activate NF- $\kappa$ B non-canonically (Battagello et al. 2020; Sun 2017). Hence it can be explained that the hyperactive p38 MAPK and their cross-talk activation of $\mathrm{NF}-\kappa \mathrm{B}$ pathway might be the reason for the inflammation, thrombosis, and vasoconstriction in COVID-19 (Grimes and Grimes 2020) The damaged human self DNA at later stages of COVID-19 can excessively activate STING (stimulator of interferon (IFN) genes) which leads to the production of IFN- $\beta$ through activation of interferon regulatory factor 3 (IRF 3). Furthermore, the human STING stimulates $\mathrm{NF}-\kappa \mathrm{B}$ resulting in "cytokine storm" (Jean-Marie Berthelot 2020). At later stages interferons cause detrimental effects through enhanced delayed innate immune response, which has been reported in SARS-CoV and MERS-CoV infections in humans (Shalhoub et al. 2015; Channappanavar and Perlman 2017).

\section{NF-KB pathway- the link between metabolic syndrome and COVID-19?}

Apart from association with the "cytokine storm", the $\mathrm{NF}-\kappa \mathrm{B}$ pathway is well known to be associated with the pathogenesis of metabolic syndrome (Baker et al. 2011; Urso 2020). Diabetes and obesity are attributed to a chronic inflammatory state, with high levels of glucose and free fatty acids in the body. This glucolipotoxicity, along with the inflammatory state, has a role in activation of the non-canonical NF- $\kappa \mathrm{B}$ pathway. In the presence of insulin resistance the glycogen synthase kinase beta (GSK3 $\beta$ ) get activated and blocks heat shock protein 70 which inhibits NF- $\mathrm{KB}$. Thus $\mathrm{NF}-\kappa \mathrm{B}$ signalling triggers a severe inflammatory response.
Moreover the downstream products of NF- $\kappa \mathrm{B}$ signalling such as iNOS and Nitric oxide block insulin signalling leading to worsening of the metabolic state (Krause et al. 2020). There was a study conducted on mice which showed the association of insulin resistance with $\mathrm{NF}-\kappa \mathrm{B}$ activation via NIK (NF-кB inhibitory kinase) (Malle et al. 2015). The hyperglycemic state in these patients activates TNF- $\alpha$ which in turn accelerates the activation of $N F-\kappa B$ pathway via the non-canonical pathway (Hattori et al. 2000). NF- $\kappa \mathrm{B}$ is also known to be associated with atherosclerosis and vascular endothelial damage, which are predominant factors for endorgan damage in patients with metabolic syndrome. Thus the overnutrition, obesity-induced excess metabolites, hyperlipidemia and hyperglycemia, are risk factors that initiate and propagate hyper-activation of the NF- $\kappa \mathrm{B}$ pathway, leading to severe COVID-19 and worse outcomes (Catrysse and Loo 2017; Apicella et al. 2020; Meyerovich et al. 2018).

Along with diabetes and obesity, the NF- $\kappa \mathrm{B}$ activation is associated with complications of hypertension as well. The RAS mediated high levels of AngII in the body has been noted to activate the NF- $\mathrm{B}$ pathway via CARD11BCL10-MALT1 or CBM (caspase recruitment domain family, member 11-B-cell chronic lymphocytic leukaemia/lymphoma 10-mucosa-associated lymphoid tissue lymphoma translocation gene 1 "CBM signalosomes" which inhibit the IкB. This leads to poorly controlled hypertension and is one of the high risk factors for cardiovascular related mortality (Crowley 2014). High levels of AngII have been seen in critically ill COVID-19 patients, thereby implicating the role of the NF- $\kappa \mathrm{B}$ pathway in the hypertensive cohort $(\mathrm{Wu}$ et al. 2020b).

Large cohort studies have shown the association with severity of COVID-19 and the prevalence of comorbidities. It was reported that out of 46,248 COVID-19 patients, a large subset were suffering from hypertension $(17 \pm 7,95 \%$ confidence interval [CI] 14-22\%), followed by diabetes $(8 \pm 6,95 \%$ CI 6-11\%), cardiovascular diseases $(5 \pm 4,95 \%$

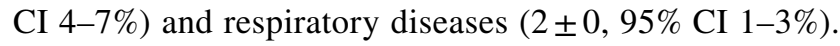
The study showed that patients who were severely ill with COVID-19, were 2.36 times more likely to have hypertension (95\% CI 1.46-3.83), 3.42 times likely to have underlying cardiovascular disease (95\% CI 1.88-6.22), 2.46 times more likely to have respiratory disease (95\% CI 1.76-3.44), when compared to those with mild disease (Dutta et al. 2020; Yang et al. 2020).

\section{Ageing and sex differences in encountering NF-KB pathway associated with COVID-19 severity}

Firstly, the slow viral alert signals due to immunosenescence in elderly patients esulted in greater viral replication and increased ACE2 shedding. Consequentially, there is increased Ang II/ADAM17 activity due to age-related 
dysregulation or alteration in RAS. The Ang II binds with AT1R constitutively activates NF- $\kappa B$ leads to vasoconstriction and inflammation and this could explain importance of age in COVID-19 severity (Sward 2020; Muller 2020). The activated innate immunity in older patients also induces a proinflammatory profile regulated by NF- $\mathrm{KB}$ pathway (inflammaging) as their adaptive immunity too declined due to immunosenescence (Sanghai and Tranmer 2020; Salminen et al. 2008). Moreover, the low levels of testosterone and estradiol (steroid hormones) in aged men and postmenopausal women, respectively fails to inhibit NF- $\mathrm{kB}$ thereby producing higher levels TNF $\alpha$ and IL-6 leads to increased risk of lung damage (Al-Lami et al. 2020) The oxidative stress, antioxidant deprivation mechanism, increased ROS and chronic low inflammation in the lungs of elderly patients might also contribute to the severity of COVID-19 via NF- $\mathrm{kB}$ - toll-like receptor signalling pathway (DelgadoRoche and Mesta 2020). Inflammaging and immunosenescence in elderly highly contribute to the development of cytokine storm. Apart from these age -related risks, cytokine storm and fatalities were also reported in young and middle-aged men might be because of genetic predisposition, virulence of viral load, epigenetic dysregulation due to life style factors and hyperactive responses by diversified immune cells. The data from epidemiological studies revealed sex-specific differences in the incidence and mortality in COVID-19 patients, where the mortality rate of men is more than female. Most of genes associated with immune regulation are encoded by $\mathrm{X}$-chromosomes, the genetic factor, extra $\mathrm{X}$ chromosomes endow an active immune cells in women (Al-Lami et al. 2020; Maleki Dana et al. 2020). Such efficient controlled innate immunity quickly recognise the virus and clear the viral load at first line of defence and thus avoiding the sustained activation of inflammatory signalling results in cytokine storm (Mueller et al. 2020). The attenuation of NF- $\mathrm{kB}$ pathway by sex hormone oestrogen reduce the cytokine production in female patients especially, the periovulatory dosages of oestrogen are very effective in inhibiting the cytokines IL-6, IL-8 and TNF- $\alpha$. The activation of oestrogen receptor $\alpha$ by hormone replacement therapy in postmenopausal women inhibits NF-KB mediated inflammation response and cytokine production (Al-Lami et al. 2020).

\section{NF-kB pathway and extrapulmonary manifestations of COVID-19}

NF- $\kappa \mathrm{B}$ has been implicated in extrapulmonary manifestations of COVID-19, which are in addition to the systemic effects due to cytokine storm. A systematic review of 22 observational studies including 17,391 COVID-19 patients reported an acute kidney injury (AKI) rate of $11 \%$, with $6.8 \%$ needing renal replacement therapy (Kunutsor and Laukkanen 2020). Both in vitro and in vivo studies have proposed that NF- $\mathrm{KB}$ activation in the renal glomerular cells via TNF- $\alpha$ and AngII has been associated with worse renal injury and need for renal support (Sanz et al. 2010). There are also reports of NF- $\mathrm{kB}$ mediated thrombotic microangiopathy within the renal microvasculature, leading to hypoxic acute tubular necrosis, leading to worse outcomes in these patients (Jhaveri et al. 2020; Hirsch et al. 2020). The cardiovascular manifestations of COVID-19 include myocardial injury, myocarditis, acute myocardial infarction, heart failure, dysrhythmias, and cortical venous thromboembolic events. Chronic activation of NF- $\mathrm{KB}$ in people with known metabolic syndromes induces vascular disturbances and remodelling of cardiomyocytes, which predisposes them to higher risk of cardiac complications (Hamid et al. 2011). This when superadded with cytokine activation can lead to cardiac injury and increases mortality risk. Similar to other viral infections like MERS, Herpes, Varicella and Cytomegalovirus which have the potential to activate the NF- $\mathrm{kB}$ pathway, COVID-19 has similar neuro-pathogenesis in cases where there is thromboembolism related neuropathy and stroke (Montalvan et al. 2020). The possible reason for this cytokine storm in COVID-19 patients might be the elevated level of anti-viral inflammatory cytokines (IL-10, IL-6, IL-2, IFN- $\gamma$ and TNF- $\alpha$ ) which were attenuated and diversified in SARS and MERS infections, respectively (Zhang et al. 2020). The involvement of IL-6, the noncanonical activation of NF- $\kappa$ B by elevated level of TNF- $\alpha$ create a degenerative feedback loop through Protein Kinase B (AKT) (Mozafari et al. 2020) and resulted in lung failure. In addition, previous reports suggested that the inflammatory cytokines TNF- $\alpha$ and IL1 $\beta$ induces the Granulocyte- Colony stimulating factor (G-CSF) via NF- $\mathrm{kB}$ pathway (Cao et al. 2014). These elevated levels of cytokine G-CSF and GMCSF found in the cytokine storm of SARS-CoV 2 induce the accelerated inflammation process in COVID-19 patients (Zhu et al. 2020).

\section{Potential therapeutic role of NF-kB inhibitors in COVID-19}

Immunomodulation at the level of NF- $\kappa \mathrm{B}$ activation and IкB degradation along with TNF- $\alpha$ inhibition will potentially result in a reduction in the cytokine storm and alleviate the severity of COVID-19 (Fig. 2). This has been proven in the SARS setting in small animal models (DeDiego et al. 2014;). There are suggestions to repurpose currently available drugs such as Cromolyn which inhibit NF- $\mathrm{KB}$ mediated cytokine production in the fight against COVID-19 (Karadesh 2020). Many of the drugs currently effective in COVID disease appear to have links to the NF- $\kappa \mathrm{B}$ cascade of immune regulation.

Dexamethasone is among the two glucocorticoids (prednisolone being the other) which has the inhibitory action 


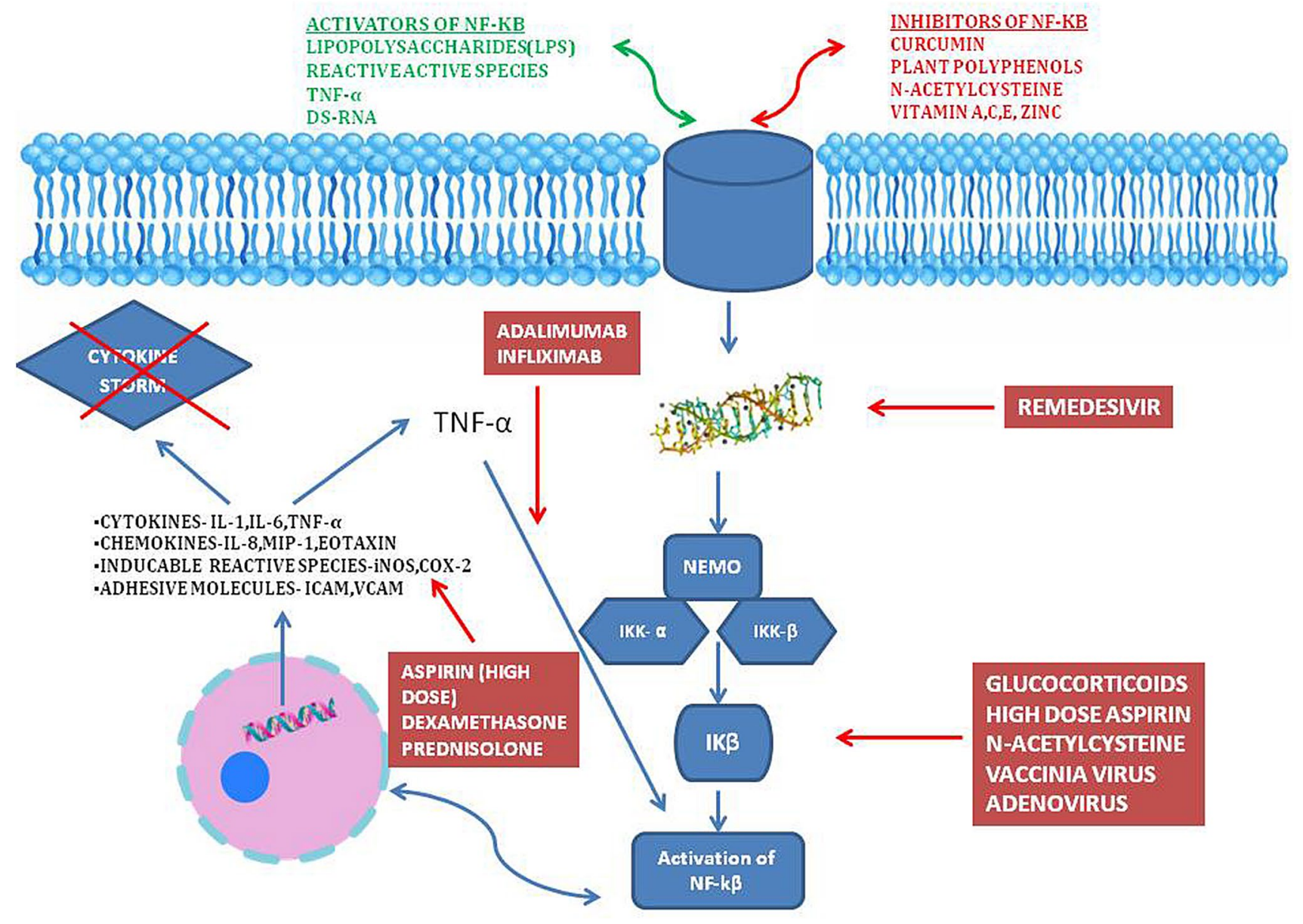

Fig. 2 Schematic diagram showing the mechanism of action of various drugs used in COVID-19 and how they inhibit the NF- $\mathrm{BB}$ pathway

on the NF-кB pathway (Ye et al. 2020; D'Acquisto et al. 2002)*. Glucocorticoids increase expression of IкB, which helps retain NF- $\mathrm{kB}$ within the cellular cytoplasm. They are also an immunomodulator, which reduces IL-6 production and activity, which in turn reduces the cytokine feedback on NF- $\kappa B$ activity (Auphan et al. 1995). In the Recovery (Randomised Evaluation of COVOD-19 Therapy) trial, dexamethasone at a dose of $6 \mathrm{mg}$ once per day for ten days, reduced deaths by one-third in ventilated patients (rate ratio 0.65 ) and by one-fifth in those eceiving oxygen therapy (rate ratio 0.80 ). The drug did not show any benefit in those getting mild to moderate disease and not requiring oxygen therapy. This supports the inference that the beneficial role of dexamethasone may be atleast partly related to the inhibition of NF- $\mathrm{KB}$ activation in the severe-critically ill COVID19 patients (The RECOVERY Collaborative Group 2020). The role of steroids generally in COVID-19 is by inhibiting the action and expression of many molecules involved in pneumonia associated inflammatory response (Ledford 2020). So it's probable that in mild and moderate disease, there isn't enough pro-inflammatory cytokines, chemokines and adhesion molecules, against which Dexamethasone can increase gene transcription of anti-inflammatory cytokines and decrease pro-inflammatory mediators (Patel et al. 2020). There are also concerns in using steroids early in the course of illness due to its risk of enhancing viral replication, reducing overall innate immunity and increasing secondary bacterial infections (Singh et al. 2020).

Remdesivir (GS-5734) is a nucleotide analogue that perturbs viral replication by inhibiting the RNA-dependent RNA polymerase. By reducing dsRNA related induction of $\mathrm{NF}-\kappa \mathrm{B}$ pathway, it reduces the cytokine storm and severe disease. In the Adaptive COVID-19 Treatment Trial (ACTT1), where Remdesivir was evaluated with the placebo, it showed quicker time to recovery for the Remdesivir patients (Beigel et al. 2020).

Hydroxychloroquine, which was initially touted as the wonder drug and used in many regimens for the treatment of COVID-19, has fallen off from popularity due to its cardiac toxicity. It reduces the levels of TNF- $\alpha$, TNF- $1 \beta$, IgG and IFN- $\gamma$, which in turn blocks the NF- $\kappa$ B pathway (Liang et al. 2018). Inhaled nitric oxide (NO) may be useful in the 
management of COVID-19 ARDS, and there is growing evidence that it reduces the inflammatory cell-mediated lung injury by inhibiting neutrophil activation and subsequent pro-inflammatory cytokines. It also works by inhibiting the $\mathrm{NF}-\kappa \mathrm{B}$ and terminates the transcription process (Matthews et al. 1996; ClinicalTrials.gov. 2020a). High dose aspirin and sulindac used in doses similar to chronic inflammatory states have potential to block NF- $\kappa \mathrm{B}$ via inhibition of TNF- $\alpha$ and IкB kinase, and are currently being investigated in clinical trials (Yamamoto et al. 1999).

Camostat Mesylate and nafamostat mesylate are serine protease inhibitors used to treat pancreatitis and inflammatory diseases could be used to combat NF- $\mathrm{KB}$ signalling pathway. These drugs are anti-inflammatory and possess anti-viral properties (Catanzaro et al. 2020). Macrolide antibiotics also have immunomodulatory actions via reduction of neutrophil-related inflammation, suppression of TNF- $\alpha$ and IL-1 reduction and mild potential for inhibition of NF-кB pathway (Cheung et al. 2010; Bleyzac et al. 2002). Though Azithromycin was used in the treatment of COVID19 initially, both on its own and along with hydroxychloroquine, the cumulative risks of QT interval prolongation and high risk of cardiac toxicity and death have reduced the enthusiasm for this combination. NF- $\mathrm{kB}$ is a redox-sensitive transcription factor, which gets activated by oxidative stress (Das 2020). Blocking this pathway with antioxidants such as Vitamin A, Vitamin C, Glutathione, Vitamin E, Zinc and many others could have both prophylactic protection and also prevent progression of illness (Nwose and Bwititi 2020; Bauer et al. 2020).

$\mathrm{N}$-acetylcysteine has been proved to have a potent NF- $\mathrm{KB}$ inhibitor via downregulating the phosphorylation of IкB. Apart from this, it also has an inhibitory action against TNF- $\alpha$ mediated activation of the NF- $\kappa$ B pathway (Oka et al. 2000). Along with direct pathway inhibition it also has antioxidant potential which reduces the reactive oxygen species (Wu et al. 2014). It was reported to have a significant clinical improvement in critically ill COVID-19 patients and is currently under assessment in a phase 4 clinical trial (Assimakopoulos and Marangos 2020; ClinicalTrials.gov. 2020b). Inhibition of TNF- $\alpha$ by the monoclonal antibodies such as Infliximab and Adalimumab, can inhibit the non-canonical activation of NF- $\kappa \mathrm{B}$ pathway which has the potential to be used to alleviate symptoms in severely ill COVID patients (Feldmann et al. 2020; Benicco et al. 2020). It was noted that out of 536 COVID-19 patients who were on regular anti-TNF- $\alpha$ as treatment for their existing inflammatory bowel disease (IBD), 448 (84\%) patients were treated as outpatient and only $84(15 \%)$ were hospitalised. Out of this only $2 \%$ either needed intensive care admission or ventilator or had death as outcome (Secure-IBD database 2020). The hormone therapy using exogenous oestrogen and testosterone also have a potential to mitigate the inflammatory response in COVID 19 patients (Al-Lami et al. 2020). These drugs which inhibit NF-kB and associated pathways targets individual mediators of maladaptive cytokines release rather than attenuating the whole immune response against COVID-19. Besides, previous reports suggests that the cytokine inhibitor therapy against TNF, IL-6, IL-17, IL-23 and IL-4 reduce undesirable inflammatory response and have no threats in viral-mediated disease progression (Schett et al. 2020). Such approaches that mitigate the exaggerated immune response (by TNF and IL-6) and which do not affect SARS-nCOV-2 clearance (by Interferon type I, IL-15 and IFN- $\gamma$ ) may exert beneficial effects against the pandemic. However, more studies are required to prove its potential effect on COVID-19 patients.

In summary, NF- $\mathrm{kB}$ pathway seems to play an important role in the natural progression of COVID and conversion to a severe phenotype. NF- $\mathrm{KB}$ inhibition may be a possible mechanism of action of currently effective drugs against COVID. More work needs to be done in identifying direct NF- $\mathrm{KB}$ inhibition as a therapeutic means of treating the severe form of this disease.

Author contributions AH: concept, critical review, data appraisal and writing the manuscript. ARH: review concept, critical appraisal, writing and revising the manuscript. SR: critical appraisal and revising the manuscript. MSR: review concept, critical appraisal and revising the manuscript. MR: supervision and final manuscript corrections.

Funding None.

\section{Compliance with ethical standard}

Conflict of Interest The authors declare that they have no conflict of interests.

Availability of data and material Not applicable for this review article.

\section{References}

Al-Lami RA, Urban RJ, Volpi E, Algburi AMA, Baillargeon J (2020) Sex hormones and novel corona virus infectious disease (COVID-19). Mayo Clin Proc. https://doi.org/10.1016/j.mayoc p.2020.05.013

Apicella M, Campopiano MC, Mantuano M, Mazoni L, Coppelli A, Del Prato S (2020) COVID-19 in people with diabetes: understanding the reasons for worse outcomes. Lancet Diabetes Endocrinol. https://doi.org/10.1016/S2213-8587(20)30238-2

Assimakopoulos SF, Marangos M (2020) $N$-acetyl-cysteine may prevent COVID-19-associated cytokine storm and acute respiratory distress syndrome. Med Hypotheses 140:109778

Auphan N, DiDonato JA, Rosette C, Helmberg A, Karin M (1995) Immunosuppression by glucocorticoids: inhibition of NF-kappaB activity through induction of IkappaB synthesis. Science 270(5234):286-290

Baker RG, Hayden MS, Ghosh S (2011) NF- $\kappa B$, inflammation and metabolic disease. Cell Metab 13(1):11 
Battagello DS, Dragunas G, Klein MO, Ayub ALP, Velloso FJ, Correa RG (2020) Unpuzzling COVID-19: tissue-related signaling pathways associated with SARS-CoV-2 infection and transmission. Clin Sci (Lond) 134(16):2137-2160. https://doi.org/10.1042/ CS20200904

Bauer SR, Kapoor A, Rath M, Thomas SA (2020) What is the role of supplementation with ascorbic acid, zinc, vitamin $\mathrm{D}$, or $\mathrm{N}$-acetylcysteine for prevention or treatment of COVID-19? Cleve Clin J Med. https://doi.org/10.3949/ccjm.87a.ccc046

Beigel JH, Tomashek KM, Dodd LE, Mehta AK, Zingman BS, Kalil AC et al (2020) Remdesivir for the treatment of COVID-19-preliminary report. NEJM. https://doi.org/10.1056/NEJMoa2007764

Benicco M, Damiani A, Infantino M, Manfredi M, Quartuccio L (2020) Old and new antirheumatic drugs for the treatment of COVID-19. Joint Bone Spine 87(3):195-197

Birra D, Benucci M, Landolfi L, Merchionda A, Loi G, Amato P et al (2020) COVID 19: a clue from innate immunity. Immunol Res 68(3):161-168

Bleyzac N, Goutelle S, Bourguignon L, Tod M (2002) Azithromycin for COVID-19: more than just an antimicrobial? Clin Drug Investig. https://doi.org/10.1007/s40261-020-00933-3

Brasier AR (2010) The nuclear factor- $\kappa \mathrm{B}$-interleukin-6 signalling pathway mediating vascular inflammation. Cardiovasc Res 86(2):211-218

Cao Y, Slaney CY, Bidwell BN, Parker BS, Johnstone CN, Rautela J, Anderson RL (2014) BMP4 inhibits breast cancer metastasis by blocking myeloid-derived suppressor cell activity. Can Res 74(18):5091-5102. https://doi.org/10.1158/0008-5472. can-13-3171

Catanzaro M, Fagiani F, Racchi M, Corsini E, Govoni S, Lanni C (2020) Immune response in COVID-19: addressing a pharmacological challenge by targeting pathways triggered by SARSCoV-2. Signal Transduct Target Therapy 5(1):1-10

Catrysse L, Loo GV (2017) Inflammation and the metabolic syndrome: the tissue specific functions of NF-kB. Trends Cell Biol 27(6):417-429

Channappanavar R, Perlman S (2017) Pathogenic human coronavirus infections: causes and consequences of cytokine storm and immunopathology. Semin Immunopathol 39(5):529-539

Cheung PS, Si EC, Hosseini K (2010) Anti-inflammatory activity of azithromycin as measured by its NF-kappaB. Inhib Activ Ocul Immunol Inflamm 18(1):32-37

ClinicalTrials.gov. Nitric oxide inhalation therapy for COVID-19 infections in the ED—full text view. https://clinicaltrials.gov/ct2/show/ NCT04338828. Accessed 11 Aug 2020

ClinicalTrials.gov. Efficacy of n-acetylcysteine (NAC) in preventing COVID-19 from progressing to severe disease. https://clinicaltr ials.gov/ct2/show/NCT04419025. Accessed 11 Aug 2020

Costela-Ruiz VJ, Illescas-Montes R, Puerta-Puerta JM, Ruiz C, Melguizo-Rodríguez L (2020) SARS-CoV-2 infection: the role of cytokines in COVID-19 disease. Cytokine Growth Factor Rev 54:62-75. https://doi.org/10.1016/j.cytogfr.2020.06.001

COVID-19 coronavirus pandemic update (2020). https://www.world ometers.info/coronavirus/? Accessed 11 Aug 2020

Crowley SD (2014) Linking angiotensin II to nuclear factor- $\kappa$ light chain enhancer of activated B cells-induced cardiovascular damage: bad CARMAs. Hypertension 64(5):933-934

D'Acquisto F, May MJ, Ghosh S (2002) Inhibition of nuclear factor kappa B (NF-B): an emerging theme in anti-inflammatory therapies. Mol Interv 2(1):22-35

Das KC (2020) c-Jun NH2-terminal kinase-mediated redox-dependent degradation of IkappaB: role of thioredoxin in NF-kappaB activation. J Biol Chem. https://www.jbc.org/content/early/2000/11/03/ jbc.M006206200.full.pdf. Accessed 11 Aug 2020
SECURE-IBD database-surveillance epidemiology of coronavirus (COVID-19) under research exclusion. https://covidibd.org/curre nt-data/. Accessed 11 Aug 2020

Day CW, Baric R, Cai SX, Frieman M, Kumaki Y, Morrey JD et al (2009) A new mouse-adapted strain of SARS-CoV as a lethal model for evaluating antiviral agents in vitro and in vivo. Virology 395(2):210-222

de Wit E, de Wit E, van Doremalen N, Falzarano D, Munster VJ (2016) SARS and MERS: recent insights into emerging coronaviruses. Nat Rev Microbiol 14:523-534

DeDiego ML, Nieto-Torres JL, Regla-Nava JA, Jimenez-Guardeño JM, Fernandez-Delgado R, Fett C et al (2014) Inhibition of NF- $\kappa B$ mediated inflammation in severe acute respiratory syndrome coronavirus-infected mice increases survival. J Virol 15:913-924

Delgado-Roche L, Mesta F (2020) Oxidative stress as key player in severe acute respiratory syndrome coronavirus (SARS-CoV) infection. Arch Med Res 51(5):384-387. https://doi.org/10.1016/j. arcmed.2020.04.019

Devaux CA, Rolain JM, Raoult D (2020) ACE2 receptor polymorphism: susceptibility to SARS-CoV-2, hypertension, multi-organ failure, and COVID-19 disease outcome. J Microbiol Immunol Infect 53(3):425-435

Dorrington MG, Fraser IDC (2019) NF-кB Signaling in macrophages: dynamics, crosstalk, and signal integration. Front Immunol 10:705

Dosch SF, Mahajan SD, Collins AR (2009) SARS coronavirus spike protein-induced innate immune response occurs via activation of the NF-kappaB pathway in human monocyte macrophages in vitro. Virus Res 142(1-2):19-27

Dutta D, Priya G, Joshi A (2020) COVID-19 and metabolic syndrome-an association too difficult to ignore. https://www.touch endocrinology.com/insight/novel-coronavirus-disease-2019-covid -19-and-metabolic-syndrome-an-association-too-difficult-to-ignor e/. Accessed 11 Aug 2020.

Feldmann M, Maini RN, Woody JN, Holgate ST, Winter G, Rowland $M$ et al (2020) Trials of anti-tumour necrosis factor therapy for COVID-19 are urgently needed. Lancet 395(10234):1407-1409

Gao YM, Xu G, Wang B, Liu BC (2019) Cytokine storm syndrome in coronavirus disease: a narrative review. J Intern Med. https://doi. org/10.1111/joim.13144

Garcia MA, Gallego P, Campagna M, Gonzalez-Santamaria J, Martinez G, Marcos-Villar L et al (2009) Activation of NF-kB pathway by virus infection requires $\mathrm{Rb}$ expression. PLoS ONE 4(7):e6422

Grimes JM, Grimes KV (2020) p38 MAPK inhibition: a promising therapeutic approach for COVID-19. J Mol Cell Cardiol. https:// doi.org/10.1016/j.yjmcc.2020.05.007

Hamid T, Guo SZ, Kingery JR, Xiang X, Dawn B, Prabhu SD (2011) Cardiomyocyte NF- $\mathrm{KB}$ p65 promotes adverse remodelling, apoptosis, and endoplasmic reticulum stress in heart failure. Cardiovasc Res 89(1):129-138

Hattori Y, Hattori S, Sato N, Kasai K (2000) High-glucose-induced nuclear factor $\mathrm{\kappa B}$ activation in vascular smooth muscle cells. Cardiovasc Res 46(1):188-197

Hirano T, Murakami M (2020) COVID-19: a new virus, but a familiar receptor and cytokine release syndrome. Immunity 52(5):731-733

Hirsch JS, Ng JH, Ross DW, Sharma P, Shah HH, Barnett RL et al (2020) Acute kidney injury in patients hospitalized with COVID19. Kidney Int 98(1):209-218

Ingraham NE, Barakat AG, Reilkoff R, Bezdicek T, Schacker T, Chipman JG et al (2020) Understanding the renin-angiotensin-aldosterone-SARS-CoV-axis: a comprehensive review. Eur Respir J. https://doi.org/10.1183/13993003.00912-2020

Jean-Marie Berthelot FL (2020) COVID-19 as a STING disorder with delayed over-secretion of interferon-beta. EBioMedicine $56: 102801$ 
Jhaveri KD, Meir LR, Chang BSF, Parikh R, Wanchoo R, BarillaLaBarca ML et al (2020) Thrombotic microangiopathy in a patient with COVID-19. Kidney Int 98(2):509-512

Karadesh AJ (2020) COVID-19: what treatments are being investigated? BMJ 368:m1252

Knoops K, Kikkert M, van den Worm SHE, Zevenhoven-Dobbe JC, van der Meer Y, Koster AJ et al (2008) SARS-coronavirus replication is supported by a reticulovesicular network of modified endoplasmic reticulum. PLoS Biol 6(9):e226

Krause M, Gerchman F, Friedman R (2020) Coronavirus infection (SARS-CoV-2) in obesity and diabetes comorbidities: is heat shock response determinant for the disease complications? Diabetol Metab Syndr 12(1):1-9

Kunutsor SK, Laukkanen JA (2020) Renal complications in COVID19: a systematic review and meta-analysis. J Ann Med. https://doi. org/10.1080/07853890.2020.1790643

Lawrence T (2009) The nuclear factor NF-kappaB pathway in inflammation. Cold Spring Harb Perspect Biol 1(6):a001651

Ledford $\mathrm{H}$ (2020) Coronavirus breakthrough: dexamethasone is first drug shown to save lives. Nature 582:469

Li Q, Verma IM (2002) NF-kappaB regulation in the immune system. Nat Rev Immunol 2(10):725-734

Liang N, Zhong Y, Zhou J, Liu B, Lu R, Guan Y et al (2018) Immunosuppressive effects of hydroxychloroquine and artemisinin combination therapy via the nuclear factor- $\kappa \mathrm{B}$ signaling pathway in lupus nephritis mice. Exp Ther Med 15(3):2436

Liao QJ, Ye LB, Timani KA, Zeng YC, She YL, Ye L et al (2005) Activation of NF-kB by the full-length nucleocapsid protein of the SARS coronavirus. Acta Biochim Biophys 37(9):607-612

Liu T, Zhang L, Joo D, Sun SC (2017) NF-kB signalling in inflammation. Signal Transduct Target Ther 2:17023

Maleki Dana P, Sadoughi F, Hallajzadeh J, Asemi Z, Mansournia MA, Yousefi B, Momen-Heravi M (2020) An insight into the sex differences in COVID-19 patients: what are the possible causes? Prehosp Disaster Med. https://doi.org/10.1017/s1049023x20000837

Malle EK, Zammit NW, Walters SN, Koay YC, Wu J, Tan BM et al (2015) Nuclear factor kB-inducing kinase activation as a mechanism of pancreatic beta cell failure in obesity. J Exp Med 212(8):1239-1254

Matthews JR, Botting CH, Panico M, Morris HR, Hay RT (1996) Inhibition of NF-B DNA binding by nitric oxide. Nucleic Acids Res 12(1):2236-2242

Meusel TR, Kehoe KE, Imani F (2002) Protein kinase R regulates double-stranded RNA induction of TNF-a but not IL-Ib mRNA in human epithelial cells. J Immunol 168(12):6429-6435

Meyerovich K, Ortis F, Cardozo AK (2018) The non-canonical NF-кB pathway and its contribution to $\beta$-cell failure in diabetes. J Mol Endocrinol 61(2):1-6

Montalvan V, Lee J, Bueso T, De Toledo J, Rivas K (2020) Neurological manifestations of COVID-19 and other coronavirus infections: a systematic review. Clin Neurol Neurosurg 194:105921

Mozafari N, Azadi S, Mehdi-Alamdarlou S, Ashrafi H, Azadi A (2020) Inflammation: a bridge between diabetes and COVID-19, and possible management with sitagliptin. Med Hypotheses. https://doi. org/10.1016/j.mehy.2020.110111

Mueller AL, McNamara MS, Sinclair DA (2020) Why does COVID19 disproportionately affect older people? Aging 12:9959-9981. https://doi.org/10.18632/aging.103344

Nwose EU, Bwititi PT (2020) Complementary antioxidant medicine in COVID-19 management and the place of haematology evaluation: brief critical and scoping review-based commentary. Hematol Med Oncol. https://doi.org/10.15761/HMO.1000210

Oeckinghaus A, Ghosh S (2009) The NF-kappaB family of transcription factors and its regulation. Cold Spring Harb Perspect Biol 1(4):a000034
Oka S, Kamata H, Kamata K, Yagisawa H, Hirata H (2000) N-acetylcysteine suppresses TNF-induced NF-kappaB activation through inhibition of IkappaB kinases. FEBS Lett 472(2-3):196-202

Park JK, Fischer R, Dechend R, Shagdarsuren E, Gapeljuk A, Wellner M, Meiners S, Gratze P, Al-Saadi N, Feldt S, Fiebeler A, Madwed JB, Schirdewan A, Haller H, Luft FC, Muller DN (2007) p38 mitogen-activated protein kinase inhibition ameliorates angiotensin II-induced target organ damage. Hypertension 49(3):481-489. https://doi.org/10.1161/01.HYP.0000256831.33459.ea

Patel SK, Saikumar G, Rana J, Dharma J, Yatoo MI, Tiwari R et al (2020) Dexamethasone: a boon for critically ill COVID-19 patients? Travel Med Infect Dis 37:101844

Saccani S, Pantano S, Natoli G (2002) p38-Dependent marking of inflammatory genes for increased NF-kappa B recruitment. Nat Immunol 3(1):69-75. https://doi.org/10.1038/ni748

Salminen A, Huuskonen J, Ojala J, Kauppinen A, Kaarniranta K, Suuronen T (2008) Activation of innate immunity system during aging: NF-kB signaling is the molecular culprit of inflammaging. Ageing Res Rev 7(2):83-105. https://doi.org/10.1016/j. arr.2007.09.002

Sanghai N, Tranmer GK Taming the cytokine storm: repurposing montelukast for the attenuation and prophylaxis of severe COVID-19 symptoms. Drug Discov Tod 16:S1359-6446(20)30371-8. doi: https://doi.org/10.1016/j.drudis.2020.09.013

Sanz AB, Sanchez-Niño MD, Ramos AM, Moreno JA, Santamaria B, Ruiz-Ortega M et al (2010) NF- $\kappa$ B in renal inflammation. J Am Soc Nephrol 21(8):1254-1262

Schett G, Sticherling M, Neurath MF (2020) COVID-19: risk for cytokine targeting in chronic inflammatory diseases? Nat Rev Immunol. https://doi.org/10.1038/s41577-020-0312-7

Shalhoub S, Farahat F, Al-Jiffri A, Simhairi R, Shamma O, Siddiqi N et al (2015) IFN- $\alpha 2 \mathrm{a}$ or IFN- $\beta 1 \mathrm{a}$ in combination with ribavirin to treat Middle East respiratory syndrome coronavirus pneumonia: a retrospective study. J Antimicrob Chemother 70(7):2129-2132

Singh AK, Majumdar S, Singh R, Misra A (2020) Role of corticosteroid in the management of COVID-19: a systematic review and a clinician's perspective. Diabetes Metab Syndr 14(5):971-978

Soy M, Keser G, Atagündüz P, Tabak F, Atagündüz I, Kayhan S (2020) Cytokine storm in COVID-19: pathogenesis and overview of anti-inflammatory agents used in treatment. Clin Rheumatol 39(7):2085-2094

Sun S (2017) The non-canonical NF-кB pathway in immunity and inflammation. Nat Rev Immunol 17:545-558. https://doi. org/10.1038/nri.2017.52

Swärd P, Edsfeldt A, Reepalu A, Jehpsson L, Rosengren BE, Karlsson MK (2020) Age and sex differences in soluble ACE2 may give insights for COVID-19. Crit Care. https://doi.org/10.1186/s1305 4-020-02942-2

Tang Y, Liu J, Zhang D, Xu Z, Ji J, Wen C (2020) Cytokine Storm in COVID-19: the current evidence and treatment strategies. Front Immunol. https://doi.org/10.3389/fimmu.2020.01708

The RECOVERY Collaborative Group (2020) Dexamethasone in hospitalized patients with COVID-19-preliminary report. NEJM. https://doi.org/10.1056/NEJMoa2021436

Urso DL (2020) Coronavirus disease 2019 (COVID-19): a brief report. Clin Manag Issues 14(1):15-19

Williams BRG (1999) PKR; a sentinel kinase for cellular stress. Oncogene 18(45):6112-6120

Williamson EJ, Walker AJ, Bhaskaran K, Bacon S, Bates C, Morton CE et al (2020) Factors associated with COVID-19-related deaths using OpenSAFELY. Nature. https://doi.org/10.1038/s4158 6-020-2521-4

Wu X, Luo A, Zhou Y, Ren J (2014) N-acetylcysteine reduces oxidative stress, nuclear factor- $\kappa \mathrm{B}$ activity and cardiomyocyte apoptosis in heart failure. Mol Med Rep 10(2):615-624 
Wu F, Zhao S, Yu B, Chen YM, Wang W, Song ZG et al (2020) Severe acute respiratory syndrome coronavirus 2 isolate Wuhan$\mathrm{Hu}-1$, complete genome GenBank: MN908947.3. Nature 579(7798):265-269

Wu Z, Hu R, Zhang C, Ren W, Yu A, Zhou X (2020) Elevation of plasma angiotensin II level is a potential pathogenesis for the critically ill COVID-19 patients. Crit Care 24(1):290

Yamamoto Y, Yin M-J, Lin K-M, Gaynor RB (1999) Sulindac inhibits activation of the NF- $\kappa \mathrm{B}$ pathway. J Biol Chem 274(38):27307-27314

Yang J, Zheng Y, Gou X, Pu K, Chen Z, Guo Q et al (2020) Prevalence of comorbidities and its effects in patients infected with SARSCoV-2: a systematic review and meta-analysis. Int J Infect Dis 94:91-95

Ye Z, Wang Y, Colunga-Lozano LE, Prasad M, Tangamornsuksan W, Rochwerg B et al (2020) Efficacy and safety of corticosteroids in COVID-19 based on evidence for COVID-19, other coronavirus infections, influenza, community-acquired pneumonia and acute respiratory distress syndrome: a systematic review and metaanalysis. CMAJ 192(27):E756-E767
Zhang Q, Lenardo MJ, Baltimore D (2017) 30 years of NF-кB: a blossoming of relevance to human pathobiology. Cell 168(1-2):37-57

Zhang Y, Li B, Ning B (2020) The comparative immunological characteristics of SARS-CoV, MERS-CoV, and SARS-CoV-2 coronavirus infections. Front Immunol. https://doi.org/10.3389/fimmu .2020 .02033

Zhou P, Yang XL, Wang XG, Hu B, Zhang L, Zhang W et al (2020) A pneumonia outbreak associated with a new coronavirus of probable bat origin. Nature 579(7798):270

Zhu Z, Lian X, Su X, Wu W, Marraro GA, Zeng Y (2020) From SARS and MERS to COVID-19: a brief summary and comparison of severe acute respiratory infections caused by three highly pathogenic human coronaviruses. Respir Res. https://doi.org/10.1186/ s12931-020-01479-w

Publisher's Note Springer Nature remains neutral with regard to jurisdictional claims in published maps and institutional affiliations. 